\title{
Residential proximity to livestock farms is associated with a lower prevalence of atopy
}

\author{
Floor Borlée, ${ }^{1,2} \mathrm{C}$ Joris Yzermans, ${ }^{2}$ Esmeralda J M Krop, ${ }^{1}$ Catharina B M Maassen, ${ }^{3}$ \\ François G Schellevis, ${ }^{2,4}$ Dick J J Heederik, ${ }^{1}$ Lidwien A M Smit ${ }^{1}$
}

\begin{abstract}
- Additional material is published online only. To view please visit the journal online (http://dx.doi.org/10.1136/ oemed-2017-104769).

${ }^{1}$ Institute for Risk Assessment Sciences, Utrecht University, Utrecht, The Netherlands

${ }^{2}$ Netherlands Institute for Health Services Research, NIVEL, Utrecht, The Netherlands ${ }^{3}$ National Institute for Public Health and the Environment (RIVM), Centre for Infectious Disease Control, Bilthoven, The Netherlands

${ }^{4}$ Department of General Practice \& Elderly Care Medicine, Amsterdam Public Health Research Institute, VU University Medical Center, Amsterdam, The Netherlands
\end{abstract}

\section{Correspondence to}

Floor Borlée, Institute for Risk Assessment Sciences, Utrecht University, Utrecht 3584, The Netherlands; f.borlee@uu.nl

Received 15 September 2017 Revised 16 February 2018 Accepted 12 March 2018 Published Online First 30 April 2018
ABSTRACT

Objectives Exposure to farm environments during childhood and adult life seems to reduce the risk of atopic sensitisation. Most studies have been conducted among farmers, but people living in rural areas may have similar protective effects for atopy. This study aims to investigate the association between residential proximity to livestock farms and atopy among non-farming adults living in a rural area in the Netherlands.

Methods We conducted a cross-sectional study among 2443 adults (20-72 years). Atopy was defined as specific $\mathrm{lg}$ E to common allergens and/or total $\mathrm{lg} \mathrm{E} \geq 100 \mathrm{IU} / \mathrm{mL}$. Residential proximity to livestock farms was assessed as 1) distance to the nearest pig, poultry, cattle or any farm, 2) number of farms within $500 \mathrm{~m}$ and $1000 \mathrm{~m}$, and 3) modelled annual average fine dust emissions from farms within $500 \mathrm{~m}$ and $1000 \mathrm{~m}$. Data were analysed with multiple logistic regression and generalised additive models.

Results The prevalence of atopy was $29.8 \%$. Subjects living at short distances from farms ( $<327 \mathrm{~m}$, first tertile) had a lower odds for atopy compared with subjects living further away (>527 m, third tertile) (OR 0.79, 95\% Cl 0.63 to 0.98 ). Significant associations in the same direction were found with distance to the nearest pig or cattle farm. The associations between atopy and livestock farm exposure were somewhat stronger in subjects who grew up on a farm.

Conclusions Living in close proximity to livestock farms seems to protect against atopy. This study provides evidence that protective effects of early-life and adult farm exposures may extend beyond farming populations.

\section{INTRODUCTION}

It is now well established that children growing up on farms are less likely to develop allergic disease than children living in the same area but with non-farming parents. ${ }^{12}$ This protective effect seems to be retained in adulthood, since adults with earlylife exposure to a farm environment still have a lower prevalence of atopy. ${ }^{3-8} \mathrm{~A}$ few epidemiological studies indicate that not only exposure during early life is protecting but occupational farm exposures during adulthood may also prevent from atopic sensitisation. ${ }^{9-12}$ Farming families are exposed to higher loads of microbial agents and to greater microbial diversity. ${ }^{13-15}$ There is some evidence that exposure to greater microbial diversity during early life, but possibly also during adult life, prevents the development of allergic diseases. ${ }^{13} 14$ 16-18

\section{Key messages}

What is already known about this subject?

- Exposure to farm environments during childhood reduces the risk of atopic sensitisation.

- Occupational farm exposures during adulthood may also prevent from atopic sensitisation.

- The beneficial effect of farm exposure may extend to inhabitants of rural areas since livestock farm emissions spread to the environment.

\section{What are the new findings?}

- This large population-based study among non-farming subjects shows that current exposure to a livestock farm environment, assessed as residential proximity to livestock farms, seems to protect against atopy in adults.

How might this impact on policy or clinical practice in the foreseeable future?

- Recent studies have highlighted the public health impact that may result from agricultural emissions.

- This study is indicative of potential beneficial health effects when living in close proximity to livestock farms.

Although the beneficial effect of farm exposure has mainly been shown in farming families, it may extend to inhabitants of rural areas since livestock farm emissions include particles containing microorganisms. ${ }^{19}$ Previous studies have indeed shown that higher levels of microbial exposure were found in close proximity to farms. ${ }^{20-22}$ The association between atopy and farm proximity is poorly studied in the general and non-farming populations. A Danish study found an urban-rural gradient of allergic sensitisation in adults depending on their residence during childhood. ${ }^{23}$ Moreover, a German study found a similar urban-rural effect on atopic sensitisation by comparing atopy prevalence in farmers, rural, suburban and urban residents. Both studies suggest that living in a rural environment might be protective. ${ }^{24}$ Two cross-sectional studies in a rural area in the Netherlands found inverse associations between indicators of livestock farm emissions and allergic rhinitis among subjects of a general population. ${ }^{25} 26$ However, both studies lacked information on history of livestock farm 
exposure, and allergic rhinitis was based on self-reported data ${ }^{25}$ and Electronic Medical Records (EMR). ${ }^{26}$

The current study aims to investigate the association between farm proximity and atopy among 2443 non-farming adults living in a rural area with a high farm density in the Netherlands. To our knowledge this is the first study that studied the association between residential proximity to livestock farms, while taking the contribution of a farm childhood into account. Furthermore, our analysis is based on objective markers of atopy which lowers the risk of misclassification.

\section{METHODS}

\section{Study population and study design}

This study is part of the VGO study (Dutch acronym for Livestock Farming and Neighbouring Residents' Health), a cross-sectional study conducted in a rural area in the South of the Netherlands characterised by a high farm density. The study population originates from participants of a questionnaire survey $(n=14163)$ conducted in November - December 2012 which is previously described by Borlée et al. ${ }^{25}$ Questionnaire respondents who gave consent for further contact for a follow-up study, and who were not working or living on a farm were eligible for a medical survey $(n=8714)$. Based on their home addresses, twelve temporary research centres were established. Between March 2014 and February 2015, all participants living within a distance of $10 \mathrm{~km}$ of a research centre $(n=7180)$ were invited to the nearest research centre for medical examination which resulted in 2494 participants (response 34.7\%). From 2443 individuals a serum sample could be obtained (98.0\%). The medical examination included collection of serum and an extended questionnaire and height and weight measurement, more details are previous described. ${ }^{27} 28$

The study protocol (13/533) was approved by the Medical Ethical Committee of the University Medical Centre Utrecht. All 2494 subjects signed an informed consent form.

\section{Atopy: IgE serology}

In our main analyses, atopy was defined as specific serum $\operatorname{IgE}$ antibodies $\geq 0.35 \mathrm{IU} / \mathrm{mL}$ to one or more common allergens and/ or a total $\mathrm{IgE}$ higher than $100 \mathrm{IU} / \mathrm{mL}$. Specific IgE to common allergens (house dust mite, grass, cat, and dog) and total IgE levels were determined in serum with enzyme immunoassays as described before. ${ }^{29}$

\section{Livestock farm exposure}

Livestock farm proximity to the home address for each participant was determined using a geographic information system (ArcGis 10.1; Esri, Redlands, CA, USA). We used data from the Provincial databases with mandatory licenses for keeping livestock in 2012 which contained data on geographic coordinates of farms, number and type of animals, and estimated fine dust emissions from each farm per year on the basis of farm type and number of animals. The following livestock farm exposure proxies were studied for each subject: (1) distance $(m)$ to the nearest pig, poultry, cattle and any livestock farm; (2) total number of farms within 500 and $1000 \mathrm{~m}$ (pig, poultry, cattle farms and any farm (independent of animal species)); (3) inverse-distance weighted fine dust emissions from all farms within $500 \mathrm{~m}$ and $1000 \mathrm{~m}$ as described previously. ${ }^{26}$

\section{Questionnaire}

The questionnaire, collected during the medical examination, comprised among others items on symptoms and diseases, smoking habits, education, profession, current animal contact, place of birth and history of living on a farm during childhood.

\section{Data analysis}

Associations between proxies of livestock farm exposures and atopy were assessed by multiple logistic regression analysis. The distance to the nearest (specific animal type) farm and weighted fine dust emission from farms within 500 and $1000 \mathrm{~m}$ was categorised into tertiles based on an equal number of atopy cases in each category, which provides a similar variance for odds ratios across categories. The shape of the relationship between atopy and livestock farm exposure variables was further studied using a penalised regression spline. To test whether the goodness-of-fit of the models that contain splines was significantly better than linear models, we used Chi-Square tests. All models were adjusted for gender, age, smoking habits (ever smoking and packyears), education (high versus middle/low education), being born in the study area, and history of living on a farm during childhood. The presence of a specific farm animal was also adjusted for the presence of other types of farm animal species. To evaluate potential heterogeneity of effects due to a history of living on a farm, we stratified for farm childhood and tested for interaction (farm childhood * farm proximity). Data were analysed using SAS 9.4 (SAS Institute Inc. Cary, NC, USA) and R version 3.02 (www.r-project.org).

Several sensitivity analyses were conducted to investigate the robustness of our findings. First, we repeated data analyses with two alternative definitions of atopy: a positive test to at least one specific allergen, or total IgE > $>100 \mathrm{IU} / \mathrm{mL}$. Second, we studied the effect of variables associated with current contact with livestock farm animals. Third, we conducted sensitivity analyses with subjects who lived at least 5 years in their current home since we assumed that prolonged exposure might have a stronger protective effect. Fourth, we stratified analyses by 'allergic symptoms' to assess the effect of exposure on atopy in combination with symptoms and without symptoms and tested for interaction between farm proximity and allergic symptoms. Fifth, we compared associations with the number of years subjects lived in their current home and farm proximity stratified by atopy to evaluate potential migration of atopic subjects from rural areas to more urbanised areas. If selective migration due to atopic sensitisation occurred, we would expect a different relationship between the number of years they have lived in their current home (proxy for migration) and farm proximity among atopic and non-atopic individuals.

More details on the study methodology are provided in the online supplement.

\section{RESULTS}

Our study population consisted for $54.5 \%$ of females and the average age was 56.4 years (table 1 ). The prevalence of atopy was $29.8 \%$ in the total population. IgE to grass $(11.8 \%)$ and house dust mite $(11.7 \%)$ were more prevalent than IgE against cat $(5.2 \%)$ and $\operatorname{dog}(3.9 \%)$. In total $33.5 \%$ had a history of living on a farm during childhood, those were mostly raised on mixed farms with multiple animal species and crop farming (data not shown). Subjects who grew up on a farm were less often atopic compared with subjects who did not have a farm childhood history (21.6\% vs $33.9 \%$ see table 2 ).

\section{Association between livestock farm exposures and atopy}

Associations between atopy and proxies of livestock farms are shown in table 2. Subjects living at short distances from 
Table 1 Characteristics of the study population

\begin{tabular}{|c|c|}
\hline Characteristics & All $(n=2443)$ \\
\hline Age, years & $56.4 \pm 11.0$ \\
\hline Female gender & $1331(54.5)$ \\
\hline $\mathrm{BMI}^{*}$ & $27.0 \pm 4.2$ \\
\hline Ever smoker & $1403(57.4)$ \\
\hline Packyearst & $17.9 \pm 17.7$ \\
\hline Born in study area & $1831(75.0)$ \\
\hline High education $\ddagger$ & $738(30.2)$ \\
\hline History of living on a farm during childhood & $818(33.5)$ \\
\hline Contact at home or during farm visit with farm animals§ & $1014(41.5)$ \\
\hline During work/study contact with animals & $148(6.1)$ \\
\hline \multicolumn{2}{|l|}{ Atopic sensitisation } \\
\hline Atopy & $727(29.8)$ \\
\hline Total lgE $\geq 100 \mathrm{Ku} / \mathrm{L}$ & $495(20.3)$ \\
\hline Specific lgE to $\geq 1$ common allergen & $444(18.2)$ \\
\hline House dust mite lgE & $285(11.7)$ \\
\hline Grass lge & $287(11.8)$ \\
\hline Cat lgE & $127(5.2)$ \\
\hline Dog lgE & $95(3.9)$ \\
\hline \multicolumn{2}{|l|}{ Distance to the nearest farm (metres) } \\
\hline Any farm & $439 \pm 263$ \\
\hline Pig farm & $692 \pm 343$ \\
\hline Poultry farm & $873 \pm 408$ \\
\hline Cattle farm & $503 \pm 271$ \\
\hline \multicolumn{2}{|l|}{ Mean number of livestock farms within $500 \mathrm{~m}$} \\
\hline Any farm & $1.8 \pm 2.1$ \\
\hline Pig farm & $0.4 \pm 0.9$ \\
\hline Poultry farm & $0.2 \pm 0.5$ \\
\hline Cattle farm & $0.9 \pm 1.2$ \\
\hline \multicolumn{2}{|l|}{ Mean number of livestock farms within $1000 \mathrm{~m}$} \\
\hline Any farm & $9.3 \pm 5.9$ \\
\hline Pig farm & $2.3 \pm 2.6$ \\
\hline Poultry farm & $1.1 \pm 1.4$ \\
\hline Cattle farm & $4.0 \pm 2.9$ \\
\hline \multicolumn{2}{|l|}{ Modelled fine dust emission } \\
\hline $\begin{array}{l}\text { Weighted fine dust emission from farms within } 500 \mathrm{~m} \\
\text { median } \pm S D\left(\mathrm{~g}^{*} \text { year }{ }^{-1 *} \mathrm{~m}^{-2}\right)\end{array}$ & $0.07 \pm 63.12$ \\
\hline $\begin{array}{l}\text { Weighted fine dust emission from farms within } 1000 \mathrm{~m} \text {, } \\
\text { median } \pm \mathrm{SD}\left(\mathrm{g}^{*} \text { year }^{-1 *} \mathrm{~m}^{-2}\right)\end{array}$ & $1.83 \pm 12.76$ \\
\hline \multicolumn{2}{|c|}{$\begin{array}{l}\text { Data are presented as mean } \pm \text { SD or } n(\%) \text {, unless indicated otherwise. } \\
\text { *BMI: body mass index=mass }(\mathrm{kg}) /(\text { height }(\mathrm{m}))^{2} \\
\text { †Mean pack years for subjects who ever smoked. Number of pack-years = (packs } \\
\text { smoked per day) } \times(\text { years as a smoker). } \\
\text { fHigh educational level: upper vocational education or university. } \\
\S \text { Animal contact was defined as contact with animals during a farm visit in the last } \\
12 \text { months AND/OR kept farm animals for a hobby last } 5 \text { years. Farm animals were } \\
\text { horses, pigs, poultry, cows, goats and sheep. Contact was defined as touching the } \\
\text { animal and/or touching the droppings of the animal. }\end{array}$} \\
\hline
\end{tabular}

a farm ( $<327 \mathrm{~m}$, first tertile) had a lower odds for atopy compared with subjects living further away (reference category: $>527 \mathrm{~m}$, third tertile) (OR $0.79,95 \%$ CI 0.63 to 0.98 ). A statistically significantly test-for-trend was found for distance to the nearest farm and atopy which indicate a dose-response relationship. The same associations and trends were observed when analysing the distance to the nearest pig or cattle farm (first versus third tertile, pig farm: OR 0.73 , 95\% CI 0.57 to 0.93 , cattle farm: OR $0.76,95 \%$ CI 0.60 to 0.96 ). Proxies for farm density (number of farms in a radius around the home) were also associated with atopy. The number of farms and pig farms within $500 \mathrm{~m}$ was associated with a lower prevalence of atopy (per increase of one farm OR: $0.96,95 \%$ CI 0.91 to 1.00 , per increase of one pig farm OR 0.88 , 95\% CI 0.79 to 1.00). No associations were observed between atopy and farm density within $1000 \mathrm{~m}$ or modelled fine dust. In figure 1 the shape of each relationship between the distance to the nearest pig, poultry, cattle and any livestock farm and atopy are shown. The spline for atopy with distance to the nearest pig farm did not have a better fit than the linear relationship. Other splines (cow, poultry and any farm) fitted significantly $(\mathrm{P}<0.05)$ better than linear models. Figure 2 shows the shape of the relationships between atopy and the number of farms and weighted fine dust emission within a $500 \mathrm{~m}$ and $1000 \mathrm{~m}$ radius from the home. All four spline models did not fit significantly $(\mathrm{P}>0.05)$ better than linear models.

Associations between atopy and livestock farm exposures were somewhat stronger when we only considered subjects with a history of living on a farm during childhood (see table 2). Subjects with a farm childhood living at short distances from a farm or a cattle farm had a lower odds for atopy compared with subjects living further away (first versus third tertile, any farm: OR $0.61,95 \%$ CI 0.40 to 0.92 , cattle farm: OR $0.56,95 \%$ CI 0.36 to 0.89 ). A significant interaction was observed between farm childhood and distance to the nearest cattle farm ( $P$ value 0.035 ), and a borderline significant interaction was found with the number of farms within $500 \mathrm{~m}$ ( $\mathrm{P}$ value 0.070 ). Spline analysis indicate a linear relationship between atopy and distance to the nearest farm for subjects with a farm childhood: atopy prevalence increases in a monotonous manner with increasing distance to the nearest farm (results not shown). Among subjects not grown up on a farm, the relationship between atopy and distance to the nearest farm fitted significantly $(\mathrm{P}<0.05)$ better than a linear model. The spline for atopy and distance to the nearest cattle farm had a significantly ( $P$ value $<0.05$ ) better fit than the linear model for subjects who were grown up on a farm, but the spline had not a better fit than the linear model for subjects who were not grown up on a farm (results not shown). Among subjects without a farm childhood, the distance to the nearest pig farm was negatively associated with atopy (first versus third tertile, pig farm: OR $0.69,95 \%$ CI 0.52 to 0.93 ). No other significant associations were observed among subjects without a history of living on a farm during childhood.

\section{Sensitivity analyses}

Overall, associations using specific serum IgE for atopy (prevalence: $18.2 \%$ ) or $\mathrm{IgE}>100 \mathrm{IU} / \mathrm{mL}$ for atopy (prevalence: $20.3 \%$ ) were statistically less strongly significant but showed similar directions and had overlapping confidence intervals (see online supplementary table S1). No clear differences in the results were observed between the two atopy definitions.

Sensitivity analyses with adjustment for current farm animal contact or farm visits did not change the associations between livestock farm exposures (see online supplementary table S2). Sensitivity analyses with subjects that lived at least 5 years in their current home $(n=2227)$ showed slightly stronger effects; confidence intervals became narrower (see online supplementary table S2), indicating that a prolonged exposure to livestock farms might have a stronger effect. Sensitivity analyses stratified for allergic symptoms showed a similar protective effect among asymptomatic subjects $(n=1799)$ as in the total population (see online supplementary table S3). In symptomatic subjects $(n=644)$ weaker associations were observed and the test for 
Table 2 Association between atopy and livestock farm exposures in the total population $(n=2443)$, and stratified by a history of living on a farm during childhood

\begin{tabular}{|c|c|c|c|c|c|}
\hline & $\begin{array}{l}\text { All }(n=2443) \\
\text { OR }(95 \% \mathrm{CI}) \text { Unadjusted }\end{array}$ & $\begin{array}{l}\text { All }(n=2443) \\
\text { (Atopy }=29.8 \%) \\
\text { OR }(95 \% \text { Cl) Adjusted }\end{array}$ & $\begin{array}{l}\text { Farm Childhood* }(n=818) \\
\text { (Atopy }=21.6 \%) \\
\text { OR }(95 \% \text { CI) Adjusted }\end{array}$ & $\begin{array}{l}\text { Non-Farm Childhood* } \\
\text { (Atopy=33.9\%) } \\
\text { ( } \mathrm{n}=1601) \\
\text { OR }(95 \% \mathrm{Cl}) \text { Adjusted }\end{array}$ & $\begin{array}{l}\text { Interaction } \\
\text { P valuet }\end{array}$ \\
\hline \multicolumn{6}{|c|}{ Minimal distance to the nearest farm (tertiles) $\ddagger$} \\
\hline$>527 \mathrm{~m}$ & 1 & 1 & 1 & 1 & 0.122 \\
\hline $327-527 m$ & $1.06(0.86$ to 1.32$)$ & $1.06(0.85$ to 1.33$)$ & $0.82(0.53$ to 1.28$)$ & $1.16(0.89$ to 1.50$)$ & \\
\hline$<327 \mathrm{~m}$ & $0.76(0.61$ to 0.93$)$ & 0.79 (0.63 to 0.98$)$ & 0.61 (0.40 to 0.92$)$ & 0.86 (0.66 to 1.11$)$ & \\
\hline Test for trend & 0.007 & 0.029 & 0.016 & 0.245 & \\
\hline \multicolumn{6}{|c|}{ Minimal distance to the nearest pig farm (tertiles) $\ddagger$} \\
\hline$>835 \mathrm{~m}$ & 1 & 1 & 1 & 1 & 0.876 \\
\hline $558-835 m$ & $0.89(0.72$ to 1.10$)$ & $0.89(0.70$ to 1.13$)$ & 0.66 (0.40 to 1.08$)$ & $0.97(0.74$ to 1.29$)$ & \\
\hline$<558$ & 0.74 (0.60 to 0.91$)$ & $0.73(0.57$ to 0.93$)$ & 0.78 (0.49 to 1.24$)$ & 0.69 (0.52 to 0.93$)$ & \\
\hline Test for trend & 0.005 & 0.009 & 0.446 & 0.010 & \\
\hline \multicolumn{6}{|c|}{ Minimal distance to the nearest poultry farm (tertiles)‡ } \\
\hline$>1035$ & 1 & 1 & 1 & 1 & 0.093 \\
\hline $684-1035 m$ & $0.93(0.76$ to 1.16$)$ & $0.97(0.77$ to 1.22$)$ & 0.72 (0.46 to 1.14$)$ & 1.07 (0.81 to 1.40$)$ & \\
\hline$<684$ & 0.91 (0.74 to 1.13$)$ & $0.95(0.75$ to 1.20$)$ & 0.73 (0.47 to 1.14$)$ & 1.05 (0.80 to 1.38$)$ & \\
\hline Test for trend & 0.395 & 0.670 & 0.204 & 0.757 & \\
\hline \multicolumn{6}{|c|}{ Minimal distance to the nearest cattle farm (tertiles) $\ddagger$} \\
\hline$>624$ & 1 & 1 & 1 & 1 & 0.035 \\
\hline $390-624 m$ & $0.83(0.67$ to 1.03$)$ & $0.86(0.69$ to 1.08$)$ & $0.80(0.51$ to 1.25$)$ & 0.88 (0.68 to 1.14$)$ & \\
\hline$<390 \mathrm{~m}$ & $0.72(0.58$ to 0.89$)$ & $0.76(0.60$ to 0.96$)$ & $0.56(0.36$ to 0.89$)$ & 0.85 (0.65 to 1.11$)$ & \\
\hline Test for trend & 0.002 & 0.020 & 0.012 & 0.232 & \\
\hline \multicolumn{6}{|c|}{ Number of farms within $500 \mathrm{~m}$ (per farm increase) } \\
\hline Any farm & $0.94(0.91$ to 0.99$)$ & $0.96(0.91$ to 1.00$)$ & $0.90(0.83$ to 0.98$)$ & 0.98 (0.93 to 1.04$)$ & 0.073 \\
\hline Pig farm & $0.85(0.76$ to 0.95$)$ & $0.88(0.79$ to 1.00$)$ & 0.84 (0.68 to 1.03$)$ & 0.92 (0.78 to 1.07$)$ & 0.306 \\
\hline Poultry farm & $0.99(0.84$ to 1.17$)$ & $1.09(0.91$ to 1.30$)$ & 1.02 (0.76 to 1.36$)$ & 1.13 (0.90 to 1.43$)$ & 0.534 \\
\hline Cattle farm & $0.97(0.90$ to 1.04$)$ & 0.99 (0.92 to 1.08$)$ & 0.93 (0.81 to 1.08$)$ & $1.02(0.93$ to 1.12$)$ & 0.277 \\
\hline \multicolumn{6}{|c|}{ Number of farms within $1000 \mathrm{~m}$ (per farm increase) } \\
\hline Any farm & 0.99 (0.98 to 1.01$)$ & $1.00(0.98$ to 1.01$)$ & $0.98(0.95$ to 1.01$)$ & 1.00 (0.98 to 1.02$)$ & 0.105 \\
\hline Pig farm & $0.97(0.94$ to 1.01$)$ & $0.98(0.94$ to 1.02$)$ & 0.95 (0.89 to 1.01$)$ & $1.00(0.95$ to 1.04$)$ & 0.117 \\
\hline Poultry farm & 0.99 (0.93 to 1.06$)$ & 1.01 (0.95 to 1.08$)$ & 1.03 (0.92 to 1.15$)$ & $1.00(0.92$ to 1.09$)$ & 0.935 \\
\hline Cattle farm & $1.00(0.97$ to 1.03$)$ & $1.01(0.98$ to 1.05$)$ & $1.01(0.95$ to 1.07$)$ & $1.01(0.97$ to 1.05$)$ & 0.401 \\
\hline \multicolumn{6}{|c|}{ Weighted fine dust emission from farms within $500 \mathrm{~m}\left(\mathrm{~g}^{*} \mathrm{year}^{-1} * \mathrm{~m}^{-2}\right) \S$} \\
\hline$<4^{*} 10^{-4}$ & 1 & 1 & 1 & 1 & 0.470 \\
\hline $4^{*} 10^{-4}-0.29$ & $1.03(0.83$ to 1.27$)$ & $1.04(0.83$ to 1.29$)$ & $0.78(0.50$ to 1.23$)$ & $1.12(0.87$ to 1.45$)$ & \\
\hline$>0.29$ & 0.84 (0.68 to 1.04$)$ & $0.88(0.71$ to 1.10$)$ & $0.80(0.54$ to 1.19$)$ & 0.91 (0.70 to 1.18$)$ & \\
\hline Test for trend & 0.115 & 0.285 & 0.286 & 0.545 & \\
\hline \multicolumn{6}{|c|}{ Weighted fine dust emission from farms within $1000 \mathrm{~m}\left(\mathrm{~g}^{*}\right.$ year $\left.^{-1}{ }^{*} \mathrm{~m}^{-2}\right) \S$} \\
\hline$<0.69$ & 1 & 1 & 1 & 1 & 0.595 \\
\hline $0.69-3.71$ & $0.98(0.75$ to 1.14$)$ & $0.94(0.75$ to 1.17$)$ & 0.82 (0.52 to 1.29$)$ & $0.98(0.77$ to 1.26$)$ & \\
\hline$>3.71$ & 0.82 (0.67 to 1.02$)$ & 0.87 (0.69 to 1.09$)$ & 0.80 (0.52 to 1.22$)$ & 0.88 (0.67 to 1.15$)$ & \\
\hline Test for trend & 0.075 & 0.215 & 0.327 & 0.369 & \\
\hline
\end{tabular}

The association between environmental livestock farm exposure and atopy was modelled with logistic regression and expressed as OR's (OR) with $95 \%$ Cl. Analyses were adjusted for gender, age, smoking habits, education, being born in the study area, and having grown up on a farm. The presence of specific animal farm was also adjusted for the presence of other types of farm animal species. Bold typeface indicates statistical significance $(\mathrm{P}<0.05)$.

* 818 subjects were grown up on a farm, 1601 subjects were not grown up on a farm and 24 subjects had a missing answer on the question if they had lived on a farm during their childhood.

tP value of interaction between farm childhood.

¥Farm proximity.

$\S$ The distance to the nearest farm (pig, poultry, cattle and any farm) and weighted fine dust emission from farms within 500 and $1000 \mathrm{~m}$ was categorised into tertiles based on an equal number of atopy cases in each category (dummy variables).

trend was not statistically significant. However, no significant interaction was observed between indicators of farm proximity and allergic symptoms.

Atopic subjects and non-atopic subjects showed a similar negative relationship between the distance to the nearest farm and the number of years they have lived in their current home (P value interaction term: 0.439 ) (see online supplementary figure $\mathrm{S} 1$ ), suggesting that selective migration does not explain the observed associations between atopy and farming. However, a significant interaction ( $\mathrm{P}$ value 0.027 ) was observed between atopy and the number of 

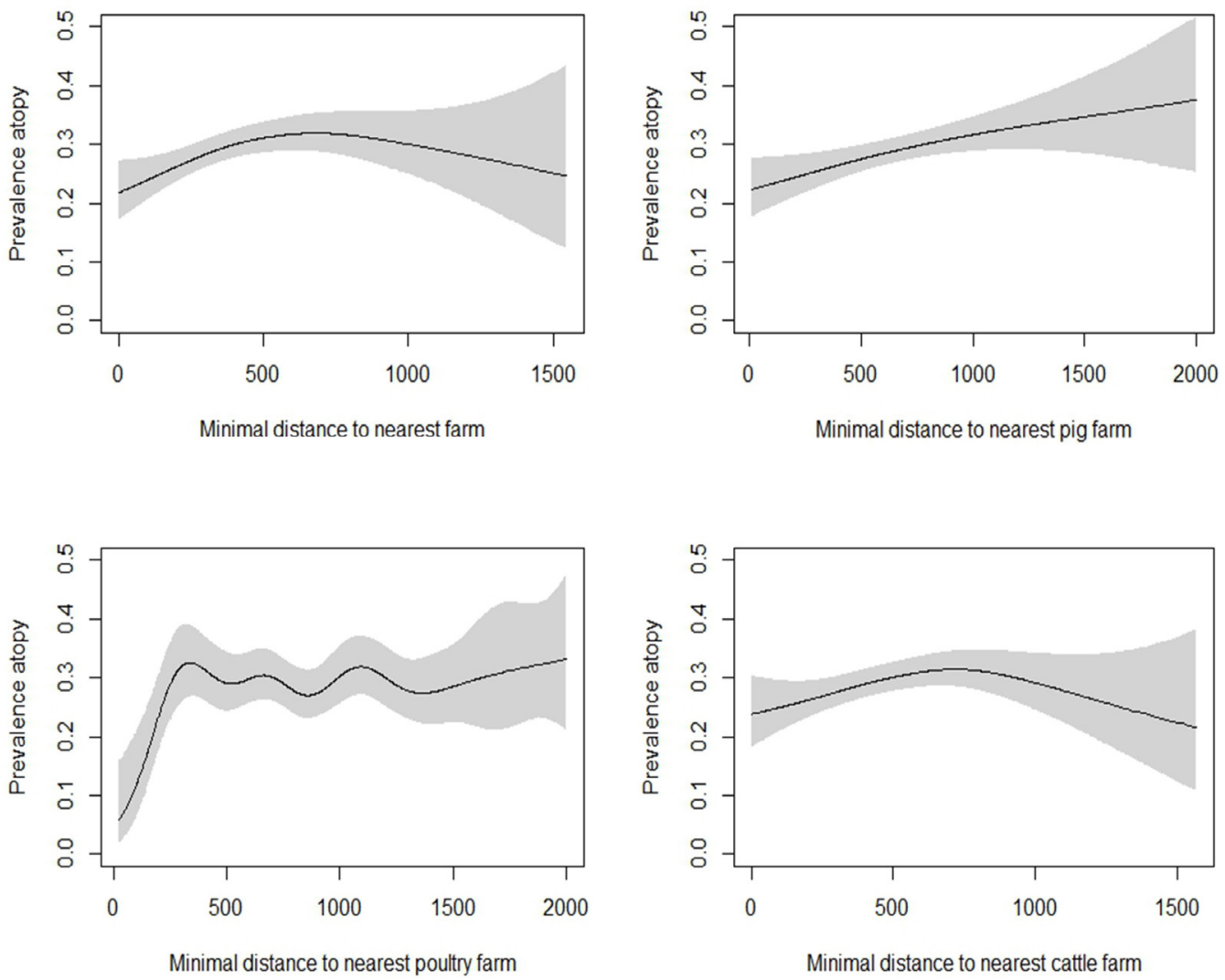

Figure 1 Associations between the distance to the nearest pig, poultry, cattle and any livestock farm and atopy in 2443 residents. Smoothed plots show the associations between the distance to the nearest pig, poultry, cattle and any farm and atopy. Associations are adjusted for gender, age, smoking habits, education, being born in the study area, and having grown up on a farm. Models on distance to specific animal farms, were also adjusted for the presence of other types of farm animal species within $1000 \mathrm{~m}$. The $P$ values of the smooth terms are: any farm: 0.025 , pig farm: 0.027, poultry farm: 0.195, cattle farm: 0.0918. The association between distance to the nearest pig farm and atopy did not fit better with a spline, indicating a linear relationship. The other spline models (cow, poultry and any farm) fitted significantly $(\mathrm{P}<0.05)$ better than the linear models.

farms within $1000 \mathrm{~m}$. This indicates that non-atopic subjects living in an area with a high farm density might migrate less frequently compared with atopic subjects (see online supplementary figure S2).

\section{DISCUSSION}

This large population-based study among non-farming subjects shows that current exposure to a livestock farm environment, assessed as residential proximity to livestock farms, seems to protect against atopy in adults. Associations were found between atopy and distance to a livestock farm, in particular to the nearest pig or cattle farm. For these associations indications for dose-response relationships were found. Proxies for farm density - such as the number of farms within $500 \mathrm{~m}$ - were also clearly associated with a lower atopy prevalence.

The study was conducted in the Netherlands which is a small country with a high population density in combination with a high livestock farm density. Farms located in the study area are a mix of small farms with relatively few animals to large farms with thousands of animals (see Table E1 Borlée $e a^{27}$ ). Pig, poultry and cattle farms were predominantly present. Goat farms are present to a lesser extent and did not show significant association with atopy (results not shown). Results of this study confirms the results of two previous studies among non-farming populations which found inverse associations between indicators of livestock farm proximity and allergic rhinitis based on self-reported data ${ }^{25}$ and EMR. ${ }^{26}$ As expected, we found that a farm childhood history was associated with a lower prevalence of atopy. Associations between atopy and livestock farm exposures were somewhat stronger among subjects who grew up on a farm. Among subjects who grew up on a farm, those living in closer proximity to livestock farms had a lower atopy prevalence than those living further away, suggesting that prolonged farm exposures may be especially effective to prevent development of atopy. Previous studies among farmers confirm our results, showing that continued involvement in farming exposure might be required to maintain optimal protection among farmers. ${ }^{3730}$

Several studies have shown that exposure to greater microbial diversity may prevent the development of allergic diseases. ${ }^{141617}$ Overall understanding how microbial diversity can protect against allergic diseases is incomplete. The microbiome - the complete microbial community that exists in the human host and is influenced by environmental exposure - seems to play an important role in the immune system in many ways. ${ }^{31}$ Regulatory T-cells (Tregs) for example, are able to inhibit the development of allergic Th2 responses. ${ }^{18}$ The microbiome influences the generation and maintenance of Tregs, among others by microbial products and microbe-microbe interactions which contribute to Treg formation and function. Allergy-promoting Th2 and Th17 responses can also be driven by the microbiome. Several microorganisms have been identified that either inhibit or promote Th2 or Th17 responses. ${ }^{31}$

We assume that farm proximity is associated with a higher diversity of environmental microbial exposure. Although we did not measure microbial diversity directly in this study, previous 

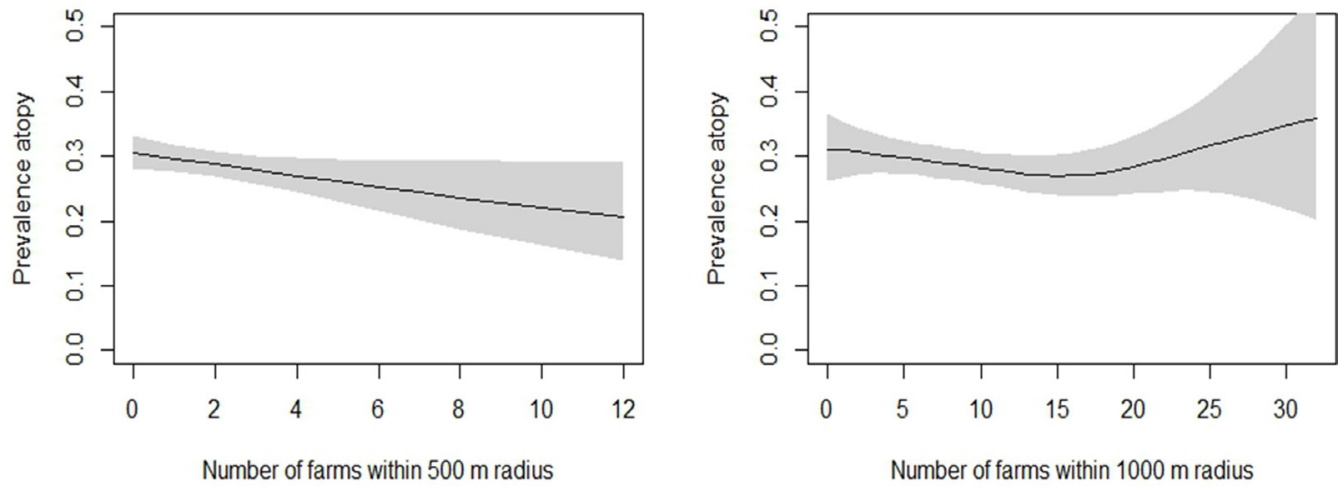

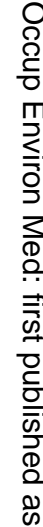
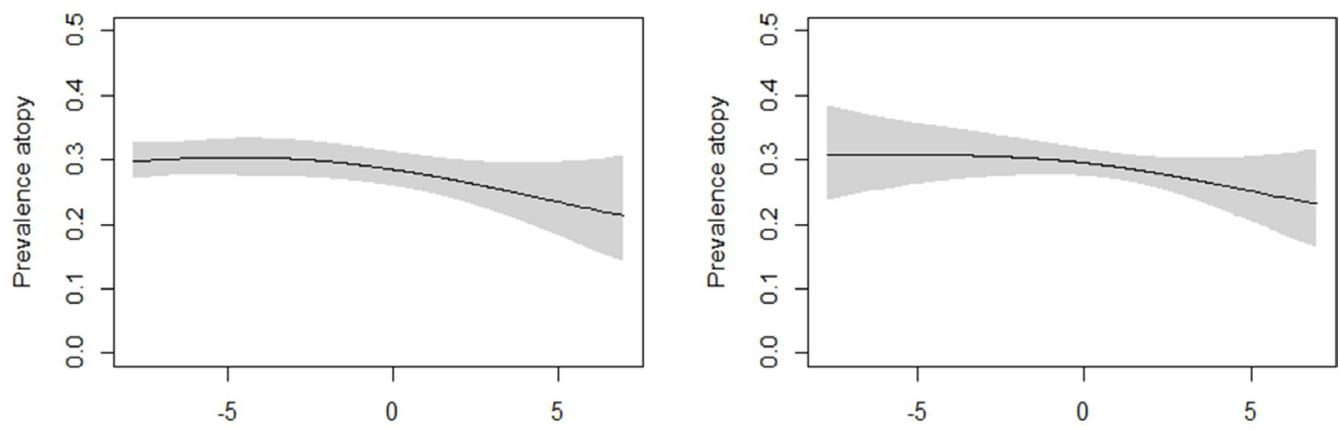

Weighted fine dust emmision from farms within $500 \mathrm{~m}$

Weighted fine dust emmision from farms within $1000 \mathrm{~m}$

Figure 2 Associations between the number of farms and weighted fine dust emission from farms within a $500 \mathrm{~m}$ and $1000 \mathrm{~m}$ radius from the home and atopy in 2443 residents. Smoothed plots show the associations between the number of farms and weighted fine dust emission within a $500 \mathrm{~m}$ and $1000 \mathrm{~m}$ radius from the home and atopy. Associations are adjusted for gender, age, smoking habits, education, being born in the study area, and having grown up on a farm. The $P$ values of the smooth terms are: number of farms within $500 \mathrm{~m}: 0.049$, number of farms within $1000 \mathrm{~m}: 0.414$, weighted fine dust emission within $500 \mathrm{~m}$ : 0.174, weighted fine dust emission within $1000 \mathrm{~m}: 0.312$. All four models with spline were not significantly $(P>0.05)$ better than the linear models.

studies show associations with residential farm proximity and other microbial agents. Elevated levels of endotoxin - cell-wall component of gram-negative bacteria - and other microbial proxies emitted from stables are measured 30-250 m downwind of farms. ${ }^{203233}$ High endotoxin levels are associated with higher microbial richness. ${ }^{17}$ As part of the VGO study, a large air measurement campaign was conducted in the study area. Based on results of this campaign, de Rooij et al evaluated whether Land-Use Regression modelling, in which farm characteristics were explored, can be used to explain spatial variation of endotoxin. ${ }^{34}$ In the current study we used general livestock characteristics as exposure proxies (eg, number of farms in buffer, distance to nearest farm). De Rooij et al found significant associations between those livestock characteristics and measured endotoxin concentrations. Especially, spatial variation of endotoxin explained by the number of farms was promising ( $\mathrm{R}^{2}$ up to 0.26 ). This provides a scientific basis for the use of general farm characteristics as exposure proxies in the current study. Although these studies support our assumption that farm proximity is associated with higher exposure to microbial diversity, further microbiological characterisation of the subjects' residential environment would help to understand the present findings.

One could argue that our exposure variables weighted fine dust emission within 500 and $1000 \mathrm{~m}$ are most reliable since these variables contain information on modelled emission of farms and it takes into account the weighted distances of those farms to the home. However, no association with atopy was observed. An explanation could be that the (microbial) composition of fine dust plays an important role. Our results showed differences between specific type of farms; we observed associations with pig and cattle farms, but no association with poultry farms. A study of Illi et al among 7682 children from rural areas showed protective effects on atopic sensitisation with cattle, but no effects with pig or poultry. ${ }^{35}$ This could indicate that the composition of emissions from farms are different between specific type of farms and may have different effects on atopy.

Another explanation for the protective effect of living near livestock farms could be migration of atopic subjects from rural areas to more urbanised areas. We showed protective effects on atopy among non-symptomatic individuals, where one would not expect health-related migration to occur. Furthermore, if selective migration due to atopic sensitisation occurred, we would expect a different relationship between the number of years they have lived in their current home and farm proximity among atopic and non-atopic individuals. Atopic subjects and non-atopic subjects showed a similar negative relationship between the distance to the nearest farm and the number of years they have lived in their current home. The significant interaction between atopy and the number of farms within $1000 \mathrm{~m}$ suggests that non-atopic subjects living in an area with a high farm density migrate less often than atopic subjects. However, overall, these sensitivity analyses do not support the hypothesis that selective migration fully explains the protective effect of farm proximity on atopy.

Detailed non-response analyses were previously conducted and we demonstrated that selection bias did not affect associations 
between farm exposures and respiratory health (among others nasal allergies). ${ }^{2527} 28$ Data on farm exposure and EMR of the general practitioner were available of the total source population (source population: $\mathrm{n}=27869^{25}$ ). This enabled us to compare characteristics of non-responders and responders in different stadia of the data collection.

In the Netherlands the wind-direction is slightly more often from southwest. South-westerly winds are associated with less stable weather conditions favouring larger dispersion of emissions. For that reason, there is usually not much difference between concentrations measured in different directions from a source and therefore the influence of wind direction and speed was not taken into account. Exposure estimates were calculated based on participants' home address, however, most people do not spend 24 hours a day at home, which could potentially lead to exposure misclassification. Adults in Europe spend most of their time indoors at home $(56 \%-66 \%),{ }^{36}$ which suggests that home address might be a reasonable proxy for individual exposure. Another potential limitation of the study is that exposure data (2012) and data of the medical examination (2014-15) were not collected at the same time which could have led to misclassification. However, we expect that long-term exposure is more relevant than current exposure since farm environments during childhood prevent from atopic sensitisation. ${ }^{12}$ Other studies have even shown that occupational farm exposures during adulthood continued to exert protective effects. ${ }^{9-12}$

To our knowledge, this is the first study investigating among non-farming residents the relationship between farm proximity and atopy based on objective markers. Despite concerns about the influence of air pollution from livestock farms on public health, our study found results that are indicative of potentially beneficial health effects of living in close proximity to farms. Our population-based study provides evidence that protective effects of early-life and adult farm exposures may extend beyond farming populations. Public health perspectives are clearly needed in the decision-making process in environmental planning and agricultural development. Although a farm environment may be beneficial for allergy prevention, one should be aware that the agents that may be responsible for the observed associations have not been identified, and therefore, causal inferences cannot be made yet. Furthermore, we and others have also shown negative health effects of air pollutants emitted from livestock farms in residential areas. ${ }^{2737-39} \mathrm{~A}$ reduction of farm emissions that may affect the airways, such as fine dust and ammonia, is required to protect neighbouring residents' health. ${ }^{40}$

Acknowledgements We would like to thank colleagues of the Institute for Risk Assessment Sciences for their contribution to the medical examination survey: Marieke Oldenwening, Siegfried de Wind, Amena Magielsen-van As, Saskia Martens, Sigrid Nieuwenweg, Anna Strumphler, Edwina Traanman, Dorine Verhoef and Jack Spithoven.

Contributors FB, LAMS, DJJH, CJY and CBMM contributed to the study concept and design. FB and EJMK coordinated and conducted the medical examination. FB performed analysis and drafted the manuscript. All authors contributed to the interpretation of the results and performed critical revision of the manuscript, and all approved the final version before submission.

Funding The Livestock Farming and Neighbouring Residents' Health (VGO) study was funded by the Ministry of Health, Welfare and Sports and the Ministry of Economic Affairs of the Netherlands, and supported by a grant from the Lung Foundation Netherlands (Grant number: 3.2.11.022).

Competing interests None declared.

Patient consent Obtained.

Ethics approval Medical Ethical Committee of the University Medical Centre Utrecht.
Provenance and peer review Not commissioned; externally peer reviewed.

Data sharing statement In consultation with the Medical Ethical Committee that approved the study protocol, data from the VGO study are not publicly available due to privacy protection ofparticipants. The study's privacy regulations statedthat only researchers from NIVEL, IRAS, and RIVM(consortium partners) have access to the studydatabase. Sharing an anonymized and de-identifieddataset is not possible as it would still containElectronical Medical Records and the personal dataof participants, which could potentially lead to theidentification of subjects. Researchers may reach aprivacy agreement to access the data by contacting DJJH (d.heederik@uu.nl) or LAMS (l.a.smit@uu.nl).

(c) Article author(s) (or their employer(s) unless otherwise stated in the text of the article) 2018. All rights reserved. No commercial use is permitted unless otherwise expressly granted.

\section{REFERENCES}

1 Campbell BE, Lodge CJ, Lowe AJ, et al. Exposure to 'farming' and objective markers of atopy: a systematic review and meta-analysis. Clin Exp Allergy 2015;45:744-57.

2 Braun-Fahrländer C, Gassner M, Grize L, et al. Prevalence of hay fever and allergic sensitization in farmer's children and their peers living in the same rural community. SCARPOL team. Swiss study on childhood allergy and respiratory symptoms with respect to air pollution. Clin Exp Allergy 1999;29:28-34.

3 Portengen L, Sigsgaard T, Omland Ø, et al. Low prevalence of atopy in young Danish farmers and farming students born and raised on a farm. Clin Exp Allergy 2002;32:247-53.

4 Radon K, Schulze A, Nowak D. Inverse association between farm animal contact and respiratory allergies in adulthood: protection, underreporting or selection? Allergy 2006:61:443-6.

5 Leynaert B, Neukirch C, Jarvis D, et al. Does living on a farm during childhood protect against asthma, allergic rhinitis, and atopy in adulthood? Am J Respir Crit Care Med 2001;164:1829-34.

6 Rennie DC, Lawson JA, Karunanayake CP, et al. Farm exposure and atopy in men and women: the Saskatchewan Rural Health Study. J Agromedicine 2015;20:302-9.

7 Douwes J, Travier N, Huang K, et al. Lifelong farm exposure may strongly reduce the risk of asthma in adults. Allergy 2007;62:1158-65.

8 Kauffmann F, Oryszczyn MP, Maccario J. The protective role of country living on skin prick tests, immunoglobulin $\mathrm{E}$ and asthma in adults from the Epidemiological study on the Genetics and Environment of Asthma, bronchial hyper-responsiveness and atopy. Clin Exp Allergy 2002;32:379-86.

9 Smit LA, Heederik D, Doekes G, et al. Occupational endotoxin exposure reduces the risk of atopic sensitization but increases the risk of bronchial hyperresponsiveness. Int Arch Allergy Immunol 2010;152:151-8.

10 Elholm G, Schlünssen V, Doekes G, et al. Become a farmer and avoid new allergic sensitization: adult farming exposures protect against new-onset atopic sensitization. J Allergy Clin Immunol 2013;132:1239-41.

11 Portengen L, Preller L, Tielen $\mathrm{M}$, et al. Endotoxin exposure and atopic sensitization in adult pig farmers. J Allergy Clin Immunol 2005;115:797-802.

12 Elholm G, Schlünssen V, Doekes $G$, et al. High exposure to endotoxin in farming is associated with less new-onset pollen sensitisation. Occup Environ Med 2018;75.

13 Braun-Fahrländer C, Riedler J, Herz U, et al. Environmental exposure to endotoxin and its relation to asthma in school-age children. N Engl J Med 2002;347:869-77.

14 Ege MJ, Mayer M, Normand AC, et al. Exposure to environmental microorganisms and childhood asthma. N Engl J Med 2011;364:701-9.

15 von Mutius E, Braun-Fahrländer C, Schierl R, et al. Exposure to endotoxin or other bacterial components might protect against the development of atopy. Clin Exp Allergy 2000;30:1230-4.

16 Karvonen AM, Hyvärinen A, Rintala $\mathrm{H}$, et al. Quantity and diversity of environmental microbial exposure and development of asthma: a birth cohort study. Allergy 2014;69:1092-101.

17 Stein MM, Hrusch CL, Gozdz J, et al. Innate immunity and asthma risk in amish and hutterite farm children. N Engl J Med 2016;375:411-21

18 Akdis CA, Akdis M. Mechanisms and treatment of allergic disease in the big picture of regulatory T cells. J Allergy Clin Immunol 2009;123:735-46. quiz 747-8.

19 Heederik D, Sigsgaard T, Thorne PS, et al. Health effects of airborne exposures from concentrated animal feeding operations. Environ Health Perspect 2007:115:298-302.

20 Thorne PS, Ansley AC, Perry SS. Concentrations of bioaerosols, odors, and hydrogen sulfide inside and downwind from two types of swine livestock operations. J Occup Environ Hyg 2009;6:211-20.

21 Schulze A, van Strien $R$, Ehrenstein V et al. Ambient endotoxin level in an area with intensive livestock production. Ann Agric Environ Med 2006;13:87-91.

22 de Rooij MM, Heederik DJ, Borlée F, et al. Spatial and temporal variation in endotoxin and PM10 concentrations in ambient air in a livestock dense area. Environ Res 2017;153:161-70.

23 Elholm G, Linneberg A, Husemoen LL, et al. The Danish urban-rural gradient of allergic sensitization and disease in adults. Clin Exp Allergy 2016;46:103-11. 
24 Filipiak B, Heinrich J, Schäfer T, et al. Farming, rural lifestyle and atopy in adults from southern Germany--results from the MONICA/KORA study Augsburg. Clin Exp Allergy 2001;31:1829-38.

25 Borlée F, Yzermans CJ, van Dijk CE, et al. Increased respiratory symptoms in COPD patients living in the vicinity of livestock farms. Eur Respir J 2015;46:1605-14.

26 Smit LA, Hooiveld M, van der Sman-de Beer F, et al. Air pollution from livestock farms, and asthma, allergic rhinitis and COPD among neighbouring residents. Occup Environ Med 2014;71:134-40.

27 Borlée F, Yzermans CJ, Aalders B, et al. Air pollution from livestock farms is associated with airway obstruction in neighboring residents. Am J Respir Crit Care Med 2017; 196:1152-61.

28 Borlée F, Yzermans CJ, Krop E, et al. Spirometry, questionnaire and electronic medical record based COPD in a population survey: Comparing prevalence, level of agreement and associations with potential risk factors. PLoS One 2017;12:e0171494.

29 Doekes G, Douwes J, Wouters I, et al. Enzyme immunoassays for total and allergen specific lgE in population studies. Occup Environ Med 1996;53:63-70.

30 Douwes J, Cheng S, Travier N, et al. Farm exposure in utero may protect against asthma, hay fever and eczema. Eur Respir J 2008;32:603-11.

31 Adami AJ, Bracken SJ. Breathing better through bugs: asthma and the microbiome. Yale J Biol Med 2016;89:309-24.

32 Dungan RS, Leytem AB, Bjorneberg DL. Concentrations of airborne endotoxin and microorganisms at a 10,000-cow open-freestall dairy. J Anim Sci 2011;89:3300-9.
33 Heederik DJJ, ljzermans CJ. Potential effects of intensive livestock farming on neighboring residents' health. IRAS, Utrecht University, NIVEL, RIVM: Utrecht, 2011.

34 de Rooij MMT, Heederik DJJ, van Nunen E, et al. Spatial variation of endotoxin concentrations measured in ambient PM10 in a livestock-dense area: implementation of a land-use regression approach. Environ Health Perspect 2018; 126:017003.

35 Illi S, Depner M, Genuneit J, et al. Protection from childhood asthma and allergy in Alpine farm environments-the GABRIEL Advanced Studies. J Allergy Clin Immunol 2012;129:1470-7.

36 Schweizer C, Edwards RD, Bayer-Oglesby L, et al. Indoor time-microenvironmentactivity patterns in seven regions of Europe. J Expo Sci Environ Epidemiol 2007;17:170-81.

37 Freidl GS, Spruijt IT, Borlée F, et al. Livestock-associated risk factors for pneumonia in an area of intensive animal farming in the Netherlands. PLoS One 2017;12:e0174796.

38 Radon K, Schulze A, Ehrenstein V, et al. Environmental exposure to confined animal feeding operations and respiratory health of neighboring residents. Epidemiology 2007; 18:300-8

39 Loftus $C$, Yost M, Sampson P, et al. Ambient ammonia exposures in an agricultural community and pediatric asthma morbidity. Epidemiology 2015;26:794-801.

40 Smit LAM, Heederik D. Impacts of intensive livestock production on human health in densely populated regions. Geohealth 2017:1:272-7. 